\title{
Effect of fetal cerebellar tissue transplantation on the restoration of hind limb locomotor function in rats with spinal cord injury
}

\author{
Medvediev V. V. ${ }^{1}$, Senchyk Yu. Yu. ${ }^{2}$, Draguntsova N. G. ${ }^{3}$, Dychko S. M. ${ }^{3}$, Tsymbaliuk V. I. ${ }^{1,3}$ \\ ${ }^{1}$ Bogomolets National Medical University, Kyiv, Ukraine \\ ${ }^{2}$ Kyiv City Clinical Emergency Hospital, Kyiv, Ukraine \\ ${ }^{3}$ A. P. Romodanov State Institute of Neurosurgery NAMS Ukraine, Kyiv, Ukraine \\ e-mail:vavo2010@gmail.com
}

\section{ABSTRACT}

Fetal cerebellar tissue contains the largest number of neurogenic progenitors committed on the differentiation into glutamatergic neurons that can be used in the development of promising new treatment for spinal cord injuries.

To evaluate the effect of fetal cerebellar tissue transplantation (FCTT) on the restoration of motor function after spinal cord injury in experiment.

MATERIALS AND METHODS. Animals: inbred albino Wistar rats (5.5 months males, weighting 300 grams); main experimental groups: 1 - spinal cord injury + transplantation of a fragment of fetal (E18) rat cerebellum $(n=15), 2-$ spinal cord injury only $(n=40)$. Model of an injury left-side spinal cord hemisection at $T_{11}$; monitoring of the ipsilateral hind limb function (IHLF) - the Basso-Beattie-Bresnahan (BBB) scale.

RESULTS. FCTT normalizes the distribution of IHLF values, distorts the dynamics of the motor function recovery, transforming it from a progressive (in a control group) to the constant with variation within 3-3.6 points BBB during the experiment. FCTT causes early temporary positive effect on the functional state of the motor system, probably provided by mediator-dependent, neuroprotective, proangiogenic effect and remyelination. In our view, the gradual depletion of the FCTT positive effect due to resorption of the graft within the first 2 months is compensated by autoregenerative neoplastic process that is typical for the control group and by autoimmune utilization of myelin-associated inhibitors of axonal growth in the zone of injury that causes stability of the IHLF value during the observation period.

CONCLUSION. Transplantation of fetal cerebellar tissue causes a short-term positive effect on the motor function recovery limited by the $1^{\text {st }}$ month of the traumatic process. Evaluation of such type of neurotransplantation effectiveness requires taking into account the dynamics of the spasticity and chronic pain.

KEYWORDS: spinal cord injury; fetal nervous tissue transplantation; motor function recovery; posttraumatic spasticity

Restoring function after spinal cord injury is one of the most difficult problems of modern biomedical science that has practical and essential fundamental importance and serves as a verifier of the latest achievements' success in the field of regenerative medicine and neural engineering. Despite the low frequency, 2.5 million patients who have suffered spinal injury were mostly of working age and often deeply disabled [1]. It provides significant social and economic aspects to the problem.
Currently, the vast majority of prospective methods for spinal cord injury rehabilitation are under permanent optimization in experimental conditions. Their complete clinical application is difficult for organizational reasons. They are based on two different approaches: biogenic restoration of descending fiber tracts of the injured spinal cord and abiogenic prosthetics of any part of the motor system. Means, based on the first approach, currently are represented by the area called «neural tissue engineering" as a version of more common areas - tissue engineering and neural engineering. 
In this context, variants of transplantation of immature cells of different origin and degree of differentiation in combination with the matrix or scaffolds are tested in order to regulate tissue reactions in the area of an injury [2]. There has been offered a variety of primary chemical and spatial structure matrices based on short sequences of bioactive peptides (Arg-Gly-Asp, Tyr-Ile-Gly-Ser-Arg), from purified proteins of natural origin (fibrin, laminin, collagen, fibronectin), synthetic matrixes (e.g., poly [N-(2-hydroxypropyl)-methacrylamid - NeuroGe ${ }^{\mathrm{TM}}$ ), hybrids with a combination of artificial (polycaprolactone, poly[lactideco-glycolide]) and natural (fibrin, collagen) polymers [2-8]. Variants of complexation include matrix combination with growth factors or stem cells of a particular phenotype [4, 6-8].

The effectiveness of the cell suspension introduction into the tissue of the spinal cord or into posttraumatic cyst is being intensively studied $[4,7]$. An example of such concept is the use of NeuroGel ${ }^{\top M}$ implantation for rehabilitation of full [9-12] or partial [13] intersection of spinal cord. The positive effect of NeuroGel ${ }^{\mathrm{TM}}$ implantation into the area of injury is associated with antihemorrhagic, immune and fibrosuppressive hydrogel properties. Reducing the duration of bleeding and minimization of the direct contact of spinal cord tissue with liquor decrease the intensity of immune responses in the area of the injury. Neuroprotective effect of NeuroGel ${ }^{\mathrm{TM}}$ is also expressed by changes in the expression of heat shock proteins HSP-25 and HSP-32 (heme oxygenase 1, HO-I) in the perifocal zone [14].

When the lesion of the spinal cord is outside the zones of limbs and diaphragm motor innervation (cervical and lumbosacral intumescence), a key problem is to restore supraspinal effects on caudal populations of motor neurons, which reduces the problem of molecular and spatial conditions for the growth of regenerating axons. Currently restoration of motor neurons populations and reinnervation of proper muscles is far from experimental solution, not to mention the creation of clinically acceptable methods [15-17].

In general, current means of neural tissue engineering can be divided into generations: I - neural tissue transplantation [18, 19]; II - implantation of amorphous matrices of different chemical composition [10, 13]; III implantation of amorphous matrices combined with immature cells $[4,8]$; IV - implantation of longitudinally tunneled matrices [20], including those associated with immature cells; V - the use of IV generation, combined with methods for growth direction of regenerating axons [21-23]. It is important to compare modern means of II-IV-generation with the efficiency of the procedures of the first generation, i.e. transplantation of natural analogues of constructed matrices - tissue fragments containing progenitors in natural environment.

Despite existing traditional sources for this type of transplantation (olfactory bulb, olfactory region of the nasal mucosa, the wall of the lateral ventricle, gyrus dentatus), in our opinion, more important is the mammalian cerebellum tissue on late terms of gestation or early postnatal period. Exactly this area of the brain has perhaps the most naturally compacted population of neurogenic progenitors and neuronal precursor of brain origin. This conclusion is due to a number of indirect but well verified arguments.

Thus, the cerebellum of adult human (and mammals in general) with an average weight of $10 \%$ by weight of the brain contains $80 \%$ of brain neurons [24], most of which are granule cells. It is small glutamatergic neurons that receive excitatory glutamatergic signals from mossy fibres (axons of neurocytes from pontine nuclei, reticular and relay nuclei) and form T-shaped processes contacting with the dendrites of GABAergic Purkinje cells - the main source of efferent connections of cerebellar cortex [25]. Granular layer of cerebellar cortex is considered a place of the densest localization of cells in the body. The diameter of the granule cells soma is $5.8 \mu \mathrm{m}$, and the size of the population in one person is $10^{10}-10^{11}$ cells [24]. In most mammalians, granule cell are formed and mature during prenatal and early postnatal period (in humans - from the third trimester of gestation to 2 years after birth) from precursors that are descendants of Atoh1-positive progenitors - cerebellar rhombic lip derivatives (domain C1), then - external granular layer. Progenitors of this layer migrate ventrally, deep into the cerebellum bud, localized between maturing Purkinje cells. Thus, in the mature cerebellum granule cells are located ventrally to pear-shaped neurons [26-28].

Due to intensive postnatal neurogenesis in the first 9 months of life, cerebellum mass increases from $5.7 \%$ to $10 \%$ of the brain mass (as on the $14-17^{\text {th }}$ week of fetal development the mass percentage is less than $5 \%$ ). Further increase of the cerebellum mass is in accordance with cerebral age indices [28]. Between 15-28 weeks of prenatal development in human the surface area of the cerebellar cortex increases by 30 times [28]. These neurometric data, a number of other facts [29-33], as well as data on the role of postnatal neurogenic progenitors' population of the cerebellum in children medulloblastoma formation [34-36] indicate the high potential of cerebellar neurogenic population at the time of birth. Rat cerebellar tissue obtained in late gestation (E18) or immediately after the birth contains perhaps the largest number of neurogenic progenitors committed to differentiation into glutamatergic neurons (granule cells).

Taking into account these data, we considered it appropriate to investigate the impact of fetal cerebellar tissue transplantation (FCTT) on the spinal cord injury and its complications - post-traumatic syndrome, spasticity and chronic pain.

\section{MATERIALS AND METHODS}

Experimental animals and experimental groups. The research was conducted in compliance with the existing rules of bioethics, namely: European Communities Council Directives of 24 November 1986 (86/609/EEC), the European Convention for the protection of vertebrate animals used for experimental and scientific purposes (1986) and the Law of Ukraine №3447-IV «On protection of animals from cruelty» (21.02.2006). Male outbred albino rats of the Wistar strain were used in this experiment (aged 5.5 months, weighing about 350 grams). Animals kept in standard conditions of vivarium in A. P. Romodanov State Institute of Neurosurgery NAMS Ukraine, receiving proper food with free access to food and water.

We formed the following experimental groups:

1) group «control-1»: model of spinal cord injury $(n=16$; maximum observation period - 24 weeks);

2) group "control-2»: an integrated comparison group, formed during 2006-2015 (including animals of the «control-1»); model of spinal cord injury, the biological characteristics and conditions of the animals are similar ( $n=40$; maximum observation period -16 weeks).

3) fetal cerebellar tissue transplantation - «FCTT» group: model of spinal cord injury and an allogeneic fetal cerebellar tissue was immediately transplanted in the injured area $(n=15$; maximum observation period - 24 weeks).

The material used for transplantation. Fetal cerebellar tissue was prepared from rat fetuses of gestation day 18 (E18). Pregnant female rats were anesthetized intraperitoneally with a $15 \mathrm{mg} / \mathrm{kg}$ xylazine («Sedazin», Biowet, Poland) and $70 \mathrm{mg} / \mathrm{kg}$ ketamine («Calypsol», Gedeon Richter, Hungary). A uterus with fetuses was isolated. The animal was euthanized by overdose of these drugs. The head of fetuses was dissected and the brain was removed. The cerebellum was isolated and each hemisphere was cut into two approximately equal parts the size of $2 \mathrm{~mm}^{3}$. A dissociated cell suspension in MEM medium (Sigma, USA) was prepared from one fragment. Cell viability was tested by trypan blue staining and cells were counted using Goryaev's chamber. The number of viable cells was $76 \pm 5 \%$. By the time of transplantation, the fragments were kept in isotonic saline at $37^{\circ} \mathrm{C}$. Cerebellar tissue, obtained from one fetus, was used for transplantation into two animals. Within one day 5 transplantations were performed with a total duration of 2.5 hours. 
Modelling of spinal cord injury. Surgery was performed under anaesthesia by intraperitoneal injection of $15 \mathrm{mg} / \mathrm{kg}$ xylazine and $70 \mathrm{mg} / \mathrm{kg}$ ketamine. Animals were fixed on a special operating table, maintaining necessary for xylazine anaesthesia temperature. Detailed technical and surgical features of spinal cord injury model (cross-section of half of the spinal cord) we have described in a previous paper [37].

In aseptic condition the skin was cut on the line of T8-L2 spinous processes. The T9-L1 spinous processes were skeletonized, intervertebral foramen was perforated. A lateralized left-sided laminectomy at T11 was performed, preserving the articular facets and opening maximally the posterior lateral surface of the spinal cord. The tissue of spinal cord was pierced with ophthalmic scalpel near the posterior median artery perpendicular to the dorsal surface of the spinal cord. One branch of ophthalmic scissors was inserted in the wound and dissected half of the spinal cord with control of the dissection completeness. In animals of «FCTT» group, we implanted $\sim 2 \mathrm{~mm}^{3}$ fragment of fetal cerebellar tissue in the spinal cord wound when bleeding stopped. In animals in all experimental groups, the access to the vertebral canal was covered with a fragment of subcutaneous fascia. The skin and soft tissue were closed twice with polyamide surgical suture No. 1 (Kyivkhimvolokno, Ukraine). The wound was treated with $5 \%$ iodine spirituous solution. Bicillin-5 (Kyivmedpreparat, Ukraine) 150-200 000 units per animal was subcutaneously injected in the neck. Dexamethasone solution (KRKA, Slovenia) $6 \mathrm{mg} / \mathrm{kg}$ was administered intraperitoneally. After these manipulations animals were kept individually for 2-4 hours in warm room $\left(30^{\circ} \mathrm{C}\right)$, further $3-6$ rats per cage at an average temperature $21-24^{\circ} \mathrm{C}$.

Registration of hind limbs function. Assessment of ipsilateral hind limb function (IHLF) was performed according to the Basso, Beattie and Bresnahan (BBB) locomotor scale [38]. Detailed description and features were considered in our previous publication [37]. The range of BBB scale is $0-21$ points; $0-11$ points take into account the movement of all three joints of the hind limb; 8-11 points analysis of a plantar support of the paw and time of weight bearing on a horizontal surface; principles of functions evaluation above 11 points are not presented. Considering the ethical rules of the work with the experimental animals, analysis of the IHLF was performed starting from the $7^{\text {th }}$ day after surgery.

Statistical analysis. Statistical analysis was performed using the Statistica 10.0 software. To evaluate the results of monitoring the spasticity and IHLF we used non-parametric Mann-Whitney U-test. Statistical significance was represented as $p$-values, the differences were considered significant at $p<0.05$. The reliability of differences IHLF and spasticity at different time of observation of each group was assessed according to Wilcoxon signed-rank test. Relationship between variables was based on Spearman's rank correlation coefficient.

\section{Control-1, 24 wk}

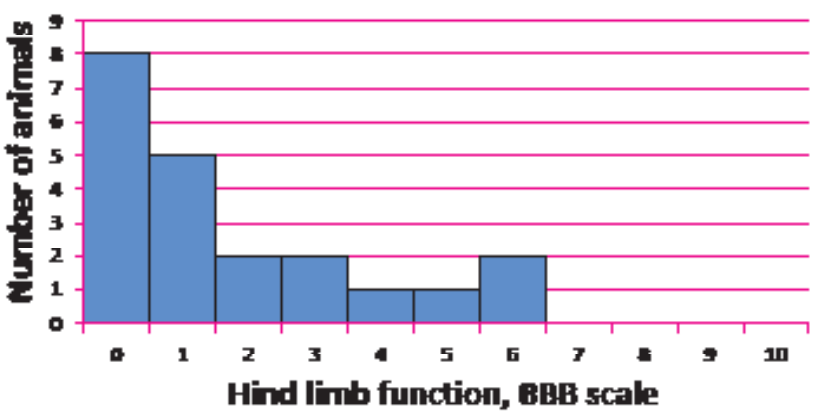

\section{RESULTS AND DISCUSSION}

Distribution analysis of the IHLF values (Fig. 1) in the control groups demonstrates the quantitative and qualitative differences between them: "control-2» group has three subgroups (0-2, 4-6 and 8-10 BBB score). Group "control-1» is missing the third subgroup, division of an interval 0-6 points is similar. Distribution of IHLF values in the "FCTT» group on the 16th and 24th week of observation differs significantly. Two subgroups are available - with the worst and best recovery. The subgroup with worse indicators of recovery, as opposed to groups "control-1" and "control-2», has a normal distribution, which is similar to the case of NeuroGel ${ }^{\mathrm{TM}}$ implantation in the zone of the spinal cord injury [13]. This, in our opinion, demonstrates the limitations of pathological tissue reactions, which change normal distribution of functional indicators of fibres dissection completeness in the ipsilateral part of the spinal cord. During application of this model, there naturally remains a certain amount of fibres of the ipsilateral spinal cord part, which do not undergo full section. Due to a stochastic approach, the number of fibres in a group of animals is a value that must be characterized by a normal distribution.

The presence of relatively intact fibres of the injured spinal cord is the basis for auto-regeneration and recovery of limb function. In this case, the efficiency of hind limb function restoration depends on the amount of fibres in animal. Thus, IHLF should have a normal distribution in a period sufficient for the regeneration process involving these fibres. However, secondary alterations of fibres, which remain whole while injury modelling, their demyelination and degeneration under the influence of inflammation near the site of injury reduce their number. Distribution of these alterative reactions among animal groups is not known; therefore, their presence should distort the original normal distribution of IHLF. Limiting of these reactions, in contrast, is a factor in the preservation of normal distribution IHLF that we observe in «FCTT» group.

The presence of a subgroup with better indicators of recovery, in our opinion, demonstrates the existence of more significant difference in the completeness of intersection of the descending tracts of ipsilateral part of the spinal cord in «FCTT» group providing a similar feature in both control groups of comparisons within pairs «FCTT»-»Control-1», «FCTT»-«Control 2» is legitimate. Exclusion of animals with the best indicators of recovery reduces the efficiency of restorative process in the «FCTT» group, but does not affect its dynamics.

Dynamics of IHLF in the «FCTT» group is characterized by lack of progression (Fig. 2). There was not such extraordinary fact in any of the previously experiments with modelling of spinal cord injury. During the entire period of observation, we found no significant changes in average group value of IHLF. At the end of the $1^{\text {st }}$ week IHLF value was $3.6 \pm 0.8$ points on BBB scale that truly dominated the values of the «Control-1» $(p=0.007)$ and «Control-2» $(p=0.01)$ groups. Significant difference with the rate of «Control-1» maintained for another 2 weeks. Its disappearing

\section{FCTT, 24 wk}

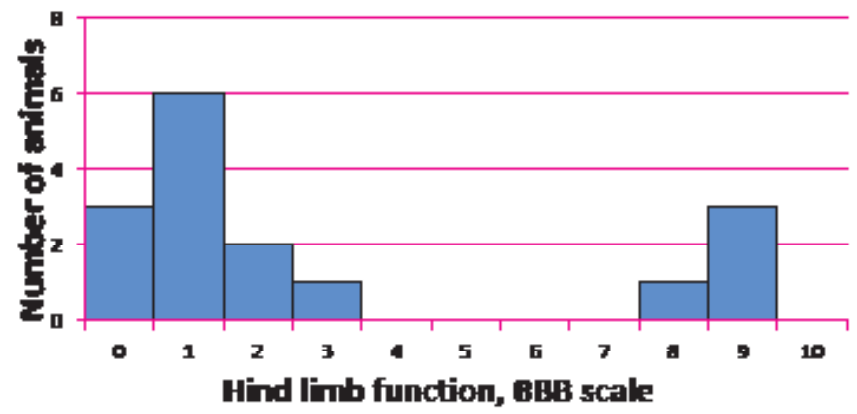




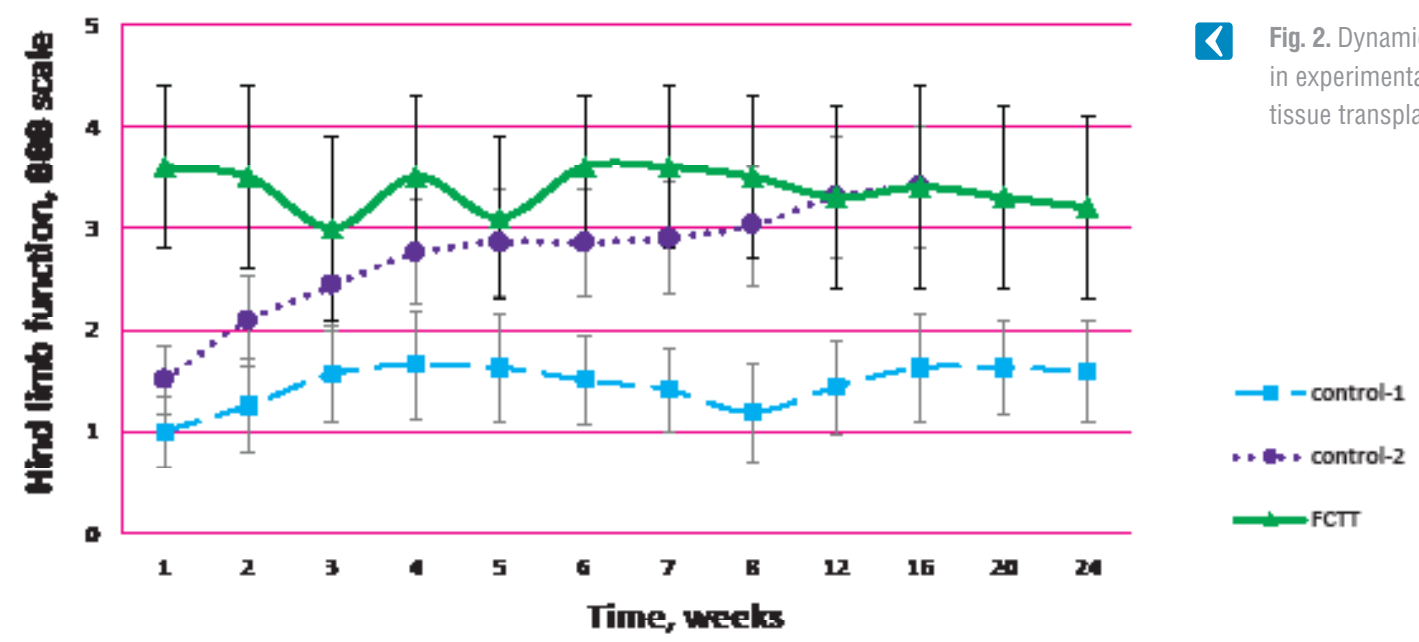

during 3-5 weeks is due not only to the IHLF decrease in «FCTT» group, but to steady significant increase in control groups.

During the observation IHLF value in the «FCTT» group varied in the range 3-3.6 BBB points. Within 6-8 weeks we noted a reliable preference of IHLF values in «FCTT» group above the «control-1» group against unreliable reduction of IHLF in this group (within 5-8 weeks) and unreliable increasing of IHLF values in «FCTT» group (within 6 weeks). On the $12^{\text {th }}$ and $16^{\text {th }}$ week we registered equal IHLF values in «FCTT» and "Control-2» groups (respectively, $3.3 \pm 0.9$ and $3.4 \pm 1.0 \mathrm{BBB}$ points). At $24^{\text {th }}$ week IHLF in «FCTT» group amounted to $3.2 \pm 0.9 \mathrm{BBB}$ points and inferior to the value of the $1^{\text {st }}$ week of observation unreliably $(p=0.144)$. Significant differences of control groups IHLF at this stage of observation was not found.

Dynamics IHLF in the "Control-1» is different (Fig. 2). Starting the recovery process with IHLF $1.0 \pm 0.35$ points, during the first month the animals are increasing (from the $3^{\text {rd }}$ week - significantly, $p=0.018$ and $p=0.043$ comparatively to the values of the $1^{\text {st }}$ and $2^{\text {nd }}$ week) the function to the mean $1.66 \pm 0.54 \mathrm{BBB}$ points (the end of the $4^{\text {th }}$ week). Later we observed equal unreliable IHLF regression with a minimum at the end of the $8^{\text {th }}$ week ( $1.19 \pm 0.48$ points $\left.\mathrm{BBB}\right)$ and significant recovery to the level of $1.63 \pm 0.46$ points after 16 weeks ( $p=0.018$ compared to the $8^{\text {th }}$ week). By the end of the experiment significant changes of IHLF was not found (24 week $-1.59 \pm 0.49 \mathrm{BBB}$ points).

Dynamics of IHLF in the "Control-2» group is different from that for «Control-1» group quantitatively (Fig. 2). Two reliable phases of the regeneration process are available: 1-8 weeks and 8-16 weeks of observation. Unlike "Control-1" group the first phase is completed with stabilization of IHLF values (5-7 $7^{\text {th }}$ week, $2.86 \pm 0.53 \mathrm{BBB}$ points). Two-phase character of IHLF dynamics for used models, which was not previously noted because of weak expressiveness [24], available in the "Control-1» and introduced in an integrated group «Control-2». By the $16^{\text {th }}$ week IHLF in the «Control-2» was $3.41 \pm 0.59$ points BBB. Significant differences between the values of IHLF in groups «control-1» and «control-2» were not found.

Based on our results and literature data, we consider it appropriate to propose the following speculative explanation for revealed features of the IHLF dynamics in the «FCTT» group. In previous studies [13], we found that implantation of regenerative matrix NeuroGel ${ }^{\mathrm{TM}}$ in the area of spinal cord injury had reliable positive functional effect already after 1 week, associated probably with antihemorrhagic, immunogenic and fibrosuppressive properties of the implant. Reduction of the bleeding limits the imbibition of perifocal zone with blood, exposure and intensity of the immune system stimulation by spinal cord antigens. Neuroprotective effect of NeuroGel ${ }^{\mathrm{TM}}$ is also expressed by changes in the expression of heat shock proteins HSP-25 and HSP-32 in the spinal cord tissue [14]. IHLF value during the first two weeks after FCTT and NeuroGel ${ }^{\mathrm{TM}}$ fragment implantation differ unreliably. It is difficult to argue the degree of tissue reactions similarity in the two experimental situations.

Fetal cerebellar tissue in this period of gestation (E18) contains neurotropic growth factors, which in intact conditions regulate migration

of precursor and maturation cells-grains, formation of T-shaped axons and generation of cerebellum neuronal networks. These factors include ephrins, semaphorins, netrins, cadherins, and compounds of FGF, Wnt and BMP families; proteins Shh, PDGF and VEGF [39-43]. In our opinion, in the case of spinal cord injury mediated by cytokines neuroprotection, rapid activation of angiogenesis and recovery of the perfusion in the perifocal zone are important in the IHLF dynamics during the first week after injury.

In the model of cerebellum injury we established the fact of a longterm (at least 2 months) persistence of immature neuronal cells in the fetal cerebellar graft, with a slow decrease in their population [25]. This determines the timeframe of significant effect of FCTT on traumatic process. It is important that auto-regeneration of spinal cord achieves the same functional result during this period. In our opinion, the temporary effects of FCTT are associated with the impact on the structural elements of the spinal cord, which possible existence in terms of the injury is determined by growth factor or metabolic support. The formation of new elements (primarily new nerve fibers) is unlikely, since it requires more time (at least 2-4 weeks) [13]. It is accompanied by a positive functional effect $\left(2-8^{\text {th }}\right.$ week $)$, which leveling is due to the metabolic deterioration in the scar comes in the late period (6-7 $7^{\text {th }}$ month) [13].

Thus, the most likely targets of FCTT are neuronal networks and transit fibers of perifocal zone. In the acute period of trauma these areas experience vascular and metabolic catastrophe, secondary alteration, demyelination and critically depends on metabolic, perfusion, anti-apoptotic support and remyelination. In case of FCTT, transplant may be a trigger of these positive effects.

Further developments include autoimmune destruction of perifocal zones tissue due to the deficiency of the barrier function of the newly formed capillaries, their damage [44]; activation of immune aggression by the transplant with the production of proinflammatory factors; utilization of transplant with reduction of positive humoral and cellular effects; mechanical compression and deformation in zone of transplantation due to the scar organization [25].

The most intensive positive impact of FCTT on the function of the cerebellum was observed within 3-4 weeks of the experiment, which is not typical for spinal cord injury [25]. Therefore, early factor or substitution cell influence of FCTT and activation of autoimmune aggression by the transplant are not enough to enhance the regeneration of the spinal cord. FCTT stimulates the autoimmune aggression on cerebellar tissue most intensive than transplantation of olfactory bulb tissue [25]. Autoimmune aggression directed against the spinal cord tissue theoretically should promote utilization of myelin debris in the area of injury - basic repellents for regenerating axons of spinal cord [13]. On our opinion, the main reason is a significant difference in the sizes of these two parts of the nervous system, i.e. in the size of regeneration substrate in the damaged organs. It is negligible in the spinal cord, compared to the cerebellum. However, it is possible that the active autoimmune utilization of axonal growth barriers from the injury zone is a factor of regeneration 
improvement during 2-3-months, i.e. due to the graft resorption against the depletion of above hypothetical mechanisms of early FCTT positive impact. If these two processes are linked (graft resorption is a trigger of autoimmune process), their impact on the dynamics of IHLF should be balanced to some extent, which is the basis for the constancy of IHLF with weakly tendency to regress.

Since the deficiency of IHLF at a higher spinal cord injury almost completely depends on the intersection of descending tracts to motoneurons, neurogenic potential of the graft may not be a key factor of regeneration. On the contrary, oligodendroglial differentiation ability of the graft, production of neuroprotective cytokines by immature cells and progenitors could serve as a positive factor for regeneration, compensate the influence of pathological agents in perifocal zone, and assist the remyelination of survived fibers of both spinal cord parts. It also promotes intergrowth of regenerating descending fibers, local remodulation of segmental neuronal networks to establish alternative polysynaptic pathways below the level of injury involving propriospinal neurons. The significance of these effects with likely negative impact of scar tissue sclerosis is limited by the duration of tissue graft persistence and its oligodendroglial component.

Another possible mechanism of early positive effect of FCTT is a mediator (synaptic or non-synaptic) impact of glutamatergic descendants of immature graft cells on the collocalized motoneurons of the injured spinal cord in a state of spinal shock (especially, L1-
L4 for adduction the hip and flexion in the hip joint). The initial stage of spinal shock is associated with the loss of glutamat-, serotonin- and noradrenergic effects on motoneurons caudally on the injury. Therefore, it prevents accurate discrete supraspinal influences that normally due to serotonin and noradrenergic long-term depolarizing effect (generation of plateau-potentials), despite its limited time and power of depolarization, causes excitation of motor neurons and muscle contraction $[45,46]$. Therefore, at spinal shock, even with single survived and functionally active synaptic supraspinal inputs into motor neurons below the level of injury, an activation of the corresponding motor units is not possible.

However, during the acute period of trauma (2-4th day in humans [47]) was observed compensatory denervation supersensitivity of motor neurons to excitatory neurotransmitter effects, in which basis is a compensatory increase in expression of $\mathrm{N}$-methyl-D-aspartate-type glutamate receptors [48]. Tissue of fetal cerebellum contains a significant amount of glutamatergic neurons progenitors. Therefore, hypothetical FCTT-dependent glutamatergic effect on proximal motor neurons in the acute and early period of spinal cord injury, while maintaining the conductivity of some survivor fibers of perifocal zone enables efficient transfer of discrete supraspinal effects on these motoneurons. That will result into early restoration of motor activity in one or two joints of ipsilateral hind limb, in this case - the hip and knee. So, for 3 points on a BBB scale (IHLF level in the «FCTT» group on the $7^{\text {th }}$ day amounted to $3.6 \pm$ 0.8 points) is characterized by movements in two joints of hind limb.

\section{CONCLUSIONS}

1. Fetal cerebellar tissue transplantation after spinal cord injury qualitatively changes the distribution of ipsilateral hind limb function in a subgroup of rats with worse recovery indicators and returns it to normal.

2. Transplantation of fetal cerebellar tissue changes the dynamics of locomotor function recovery, transforming it from a progressive course of the control groups, in constant, characterized by nonsignificant range of BBB score with a maximum on the $1^{\text {st }}, 6^{\text {th }}, 7^{\text {th }}$ and minimum on the $3^{\text {rd }}$ week.

3. FCTT causes early temporary positive effect on the efferent neurons that were under the influence of secondary post-traumatic alterative factors. Probably, is due to mediators, neuroprotective, proangiogenic and remielinisative effect of the graft.

4. Gradual reduction of FCTT positive impact due to of the graft resorption during the first 2 months is probably compensated by auto-regeneration and expansion of spinal cord tissue elements involved to the motor function that causes stability of hind limb function.

\section{REFERENCES}

1. Lee BB, Cripps RA, Fitzharris $M$, et al. The global map for traumatic spinal cord injury epidemiology: update 2011, global incidence rate. Spinal Cord. 2014; 52(2):110-16

2. Volpato FZ, Führmann T, Migliaresi C, et al. Using extracellular matrix for regenerative medicine in the spinal cord. Biomaterials. 2013; 34(21):4945-55.

3. Gu X, Ding F, Williams DF. Neural tissue engineering options for peripheral nerve regeneration. Biomaterials. 2014; 35(24):6143-56.

4. Assunção-Silva RC, Gomes ED, Sousa N, et al. Hydrogels and cell based therapies in spinal cord injury regeneration. Stem Cells International. 2015; Article ID 948040. doi.org/10.1155/2015/948040

5. Rodríguez-Vázquez $M$, Vega-Ruiz B, Ramos-Zúñiga $R$, et al. Chitosan and its potential use as a scaffold for tissue engineering in regenerative medicine. Bio Med Research International. 2015; Article ID 821279

6. Siebert JR, Eade AM, Osterhout DJ. Biomaterial approaches to enhancing neurorestoration after spinal cord injury: strategies for overcoming inherent biological obstacles. Bio Med Research International. 2015; Article ID 752572

7. Tian L, Prabhakaran MP, Ramakrishna S. Strategies for regeneration of components of nervous system: scaffolds, cells and biomolecules. Regen Biomater. 2015; 2(1):31-45. doi: 10.1093/rb/rbu017

8. Tsintou M, Dalamagkas K, Seifalian AM. Advances in regenerative therapies for spinal cord injury: a biomaterials approach. Neural Regen Res. 2015; 10(5):726-42.

9. Woerly S, Doan VD, Evans-Martin F, et al. Spinal cord reconstruction using NeuroGel implants and functional recovery after chronic injury. J Neurosci Res. 2001; 66(6):1187-197.

10. Woerly S, Doan VD, Sosa N, et al. Reconstruction of the transected cat spinal cord following NeuroGel implantation: axonal tracing, immunohistochemical and ultrastructural studies. Int J Dev Neurosci. 2001; 19(1):63-83.

11. Woerly S, Pinet E, de Robertis L, et al. Spinal cord repair with PHPMA hydrogel containing RGD peptides (NeuroGel). Biomaterials. 2001; 22(10):1095-111.

12. Woerly S, Doan VD, Sosa N, et al. Prevention of gliotic scar formation by NeuroGel allows partial endogenous repair of transected cat spinal cord. J Neurosci Res. 2004; 75(2):262-72.

13. Tsymbaliuk VI, Medvediev VV. Spinnoy mozg. Elegiya nadezhdy: monografiya [Spinal cord. Elegy of hope: a monograph]. Vinnitsa: Nova Kniga - Vinnitsa: New Book, 2010. 944 p. [in Russian] 
14. Woerly S, Awosika O, Zhao P, et al. Expression of heat shock protein (HSP)-25 and HSP-32 in the rat spinal cord reconstructed with Neurogel. Neurochem Res. 2005; 30(6-7):721-35

15. Li K, Javed E, Scura D, et al. Human iPS cell-derived astrocyte transplants preserve respiratory function after spinal cord injury. Exp Neurol. 2015; 271:479-92.

16. Dougherty BJ, Gonzalez-Rothi EJ, Lee KZ, et al. Respiratory outcomes after mid-cervical transplantation of embryonic medullary cells in rats with cervical spinal cord injury. Exp Neurol. 2016; 278:22-26.

17. Gill LC, Gransee HM, Sieck GC, et al. Functional recovery after cervical spinal cord injury: role of neurotrophin and glutamatergic signaling in phrenic motoneurons. Respir Physiol Neurobiol. 2016; 226:128-36.

18. Tsymbaliuk VI, Medvediev VV. Neyrogennye stvolovye kletki [Neurogenic stem cells]. Kiev: Koval' - Kiev: Koval, 2005. 596 p. [in Russian]

19. Döbrössy M, Busse M, Piroth T, et al. Neurorehabilitation with neural transplantation. Neurorehabil Neural Repair. 2010; 24(8):692-701.

20. Zhang Q, Yan Sh, You R, et al. Multichannel silk protein/laminin grafts for spinal cord injury repair. J Biomed Mater Res A. 2016; doi:10.1002/jbm.a.35851 [Epub ahead of print].

21. Taylor L, Jones L, Tuszynski MH, et al. Neurotrophin-3 gradients established by lentiviral gene delivery promote short-distance axonal bridging beyond cellular grafts in the injured spinal cord. J Neurosci. 2006; 26(38):9713-21.

22. Gao R, Li X, Xi Sh, al. Exogenous neuritin promotes nerve regeneration after acute spinal cord injury in rats. Hum Gene Ther. 2016; 27(7):544-54.

23. Hanna A, Thompson DL, Hellenbrand $D J$, et al. Sustained release of Neurotrophin-3 via calcium phosphate-coated sutures promotes axonal regeneration after spinal cord injury. J Neurosci Res. 2016; 94(7):645-52.

24. Lent $\mathrm{R}$, Azevedo FAC, Andrade-Moraes $\mathrm{CH}$, et al. How many neurons do you have? Some dogmas of quantitative neuroscience under revision. Eur $\mathrm{J}$ Neurosci. 2002; 35:199. doi:10.1111/j.1460-9568.2011.07923.x

25. Tsymbaliuk VI, Medvediev VV, Senchik YuY. Cerebellum, abo mozochok: monografiya [Cerebellum: monograph]. Vinnitsa: Nova Kniga - Vinnitsa: New Book, 2013. 272 p. [in Ukrainian]

26. Hashimoto M, Hibi M. Development and evolution of cerebellar neural circuits. Dev Growth Differ. 2012; 54(3):373-89.

27. Hoshino M. Neuronal subtype specification in the cerebellum and dorsal hindbrain. Dev Growth Differ. 2012; 54(3):317-26.

28. Marzban H, Del Bigio MR, Alizadeh J, et al. Cellular commitment in the developing cerebellum. Front Cell Neurosci. 2015; doi: 10.3389/fncel.2014.00450

29. Kumar M, Csaba Z, Peineau S, et al. Endogenous cerebellar neurogenesis in adult mice with progressive ataxia. Ann Clin Transl Neurol. 2014; 1(12):968-981. doi: $10.1002 / a c n 3.137$

30. Chang $J C$, Leung M, Gokozan HN, et al. Mitotic events in cerebellar granule progenitor cells that expand cerebellar surface area are critical for normal cerebellar cortical lamination in mice. J Neuropathol Exp Neurol. 2015; 74(3):261-272. doi:10.1097/NEN.00000000000000171

31. Ma M, Wu W, Li Q, et al. N-myc is a key switch regulating the proliferation cycle of postnatal cerebellar granule cell progenitors. Sci Rep. 2015; 5:1. doi: 10.1038/ srep12740

32. Leffler SR, Legué E, Aristizábal O, et al. A mathematical model of granule cell generation during mouse cerebellum development. Bull Math Biol 2016; 78(5):859878. doi 10.1007/s11538-016-0163-3

33. Zhu T, Tang $H$, Shen $Y$, et al. Transplantation of human induced cerebellar granular-like cells improves motor functions in a novel mouse model of cerebellar ataxia. Am J Transl Res. 2016; 8(2):705-18.

34. Vriend J, Ghavami S, Marzban H. The role of the ubiquitin proteasome system in cerebellar development and medulloblastoma. Mol Brain. 2015; 8(1):1-14. doi 10.1186/s13041-015-0155-5

35. Ho Y, Li X, Jamison S, et al. PERK activation promotes medulloblastoma tumorigenesis by attenuating premalignant granule cell precursor apoptosis. Am J Pathol. 2016; 186(7):1939-1951. doi: 10.1016/j.ajpath.2016.03.004

36. Dey $A$, Robitaille $M$, Remke $M$, et al. YB-1 is elevated in medulloblastoma and drives proliferation in Sonic hedgehog-dependent cerebellar granule neuron progenitor cells and medulloblastoma cells. Oncogene. 2016; doi:10.1038/onc.2015.491 [Epub ahead of print].

37. Tsymbaliuk VI, Medvediev VV, Semenova VM. Model' peretinu polovini poperechnika spinnogo mozku. I. Tekhnichni, patomorfologichni ta kliniko-eksperimental'ni osoblivosti [The Model of crossing of half transverse diameter of the spinal cord. I. Technical, pathomorphological, clinical and experimental features]. Ukr neyrokhirurg zhurnal - Ukrainian Neurosurgical Journal. 2016; 2:18-27. [in Ukrainian]

38. Basso DM, Beattie MS, Bresnahan JC. A sensitive and reliable locomotor rating scale for open field testing in rats. J Neurotrauma. 1995; 12(1):1-21.

39. Sentilhes L, Michel C, Lecourtois M, et al. Vascular endothelial growth factor and its high-affinity receptor (VEGFR-2) are highly expressed in the human forebrain and cerebellum during development. J Neuropathol Exp Neurol. 2010; 69(2):111-28.

40. Darland DC, Cain JT, Berosik MA, et al. Vascular endothelial growth factor (VEGF) isoform regulation of early forebrain development. Developmental Biology. 2011; 358:9-22.

41. Jankowski J, Miething A, Schilling K, et al. Cell death as a regulator of cerebellar histogenesis and compartmentation. Cerebellum. 2011; 10:373-92

42. Kilpatrick $D L$, Wang $W$, Gronostajski $R$, et al. Nuclear factor I and cerebellar granule neuron development: an intrinsic-extrinsic interplay. Cerebellum. 2012; 11:4149.

43. De Luca A, Cerrato V, Fuca E, et al. Sonic hedgehog patterning during cerebellar development. Cell Mol Life Sci. 2016; 73(2):291-303. doi 10.1007/s00018-0152065-1

44. Yu SW, Friedman B, Cheng Q, et al. Stroke-evoked angiogenesis results in a transient population of microvessels. J Cereb Blood Flow Metab. 2007; 27:755-63.

45. Heckman CJ, Enoka RM. Motor unit. Compr Physiol. 2012; 2:2629-82. doi: 10.1002/cphy.c100087

46. D'Amico JM, Condliffe EG, Martins KJB, et al. Recovery of neuronal and network excitability after spinal cord injury and implications for spasticity. Front Int Neurosci. 2014; 8:1-24. doi: 10.3389/fnint.2014.00036

47. Ditunno JF, Little JW, Tessler A, et al. Spinal shock revisited: a four-phase model. Spinal Cord. 2004; 42:383-95.

48. Wienecke $\mathrm{J}$, Westerdahl $A C$, Hultborn $\mathrm{H}$, et al. Global gene expression analysis of rodent motor neurons following spinal cord injury associate molecular mechanisms with development of post-injury spasticity. J Neurophysiol. 2010; 103(2):761-78.

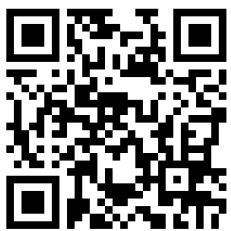

ARTICLE ON THE SITE TRANSPLANTOLOGY.ORG
The authors indicate no potential conflicts of interest.

Received: July 21, 2016

Accepted: November 04, 2016 